\title{
Mythos und Wissenschaft: ein neues Verhältnis?
}

Längere Zeit galt, im Zeichen eines strengen Szientismus, eine scharfe Trennung zwischen Wissenschaft und Mythos. Objektive, gesicherte Erkenntnis, die auf Fakten und streng erfassten GesetzmäBigkeiten beruht, gab es allein auf Seiten der Wissenschaft. Das Mythische galt als ein überholtes Zeitalter und wurde schnell mit dem Unwahren, Täuschenden, Kindlichen identifiziert. Es hatte höchstens im Dichterischen, Künstlerischen, etwas zu suchen.

Wie sieht dieses Verhältnis zwischen Mythos und Wissenschaft heute aus? Das war die Grundfrage eines Kolloquiums, das vom 14. bis 16. März in Neuchâtel stattfand. Das Kolloquium war vom dortigen Institut für Hermeneutik organisiert, in Zusammenarbeit mit einem internationalen Hermeneutik-Netzwerk, dem auch das Zürcher Institut für Hermeneutik angehört. Es war interdisziplinär konzipiert: Natur- und Humanwissenschaftler, Philosophen, Historiker, Literaturwissenschaftler und Theologen arbeiteten gemeinsam am Thema. Ein Teil des Kolloquiums fand im Dürrenmatt-Zentrum statt, wo gezeigt wurde, wie sich dieser Autor in Text und Bild mit dem Thema "Mythos und Wissenschaft" auseinandergesetzt hat.

Als Grundtenor des Kolloquiums war herauszuhören, dass das Verhältnis heute viel offener gestaltet werden muss. Wissenschaft kann nicht mehr so unmittelbar Wahrheit als solche in Anspruch nehmen. In ihrer stets revidierbaren Erforschung der Wirklichkeit braucht sie Modelle, Hypothesen. Das heißt: Zur wissenschaftlichen Forschung gehört auch Fantasie, Vorstellungskraft, welche die Wissenschaft nicht selten in den Mythen geschöpft hat und heute noch schöpft (so wurde etwa gezeigt, wie stark der alte Mythos vom Äther die Theorien vom Elektromagnetismus schöpferisch geprägt hat). Wie Dürrenmatt sagte: »Ohne das Wagnis von Fiktionen ist der Weg zur Erkenntnis nicht begehbar.«

Zugleich wurde auch betont, dass die Wissenschaft in der öffentlichen Diskussion erneut soziale, kulturelle Funktionen des alten Mythos übernimmt, ja mehr oder weniger bewusst selbst wieder zum Mythos wird. Die Aufgabe, technische Errungenschaften der Wissenschaft kritisch zu verantworten, kann mit quasimythologischen Gedankengängen elegant umgangen werden. Gerade Szientismus offenbart sich hier als ein zählebiger Mythos! 
Auch von der Theologie her wurde das Verhältnis offen diskutiert. Zwar bildet die Kritik an der Mythologie eine wichtige Wurzel der Theologie. Zugleich aber hat diese auch eng mit dem Mythischen zu tun (man denke nur an die Allgegenwart des Mythischen in der Bibel!). In diesem Rahmen wurde Rudolf Bultmanns Programm der Entmythologisierung evaluiert. In Hinsicht auf einen redlichen Umgang mit biblischen Texten und theologischen Themen in heutiger Zeit bleibt es weiterhin relevant. Zugleich aber wurde gefragt, ob der Mythos im ursprünglichen Sinne, als eine grundlegende Urerzählung, nicht wesenhaft zum christlichen Glauben gehört. Kann anders als erzählerisch über die Grunddaten des Glaubens Rechenschaft abgelegt werden?

Das rege interdisziplinäre Gespräch darf weitergehen (eine Publikation ist vorgesehen). 